\title{
12
}

\section{EMERGING INSIGHTS AND LESSONS FOR THE FUTURE}

\author{
Adrian Ely, Anabel Marin, Fiona Marshall, Marina Apgar, \\ Hallie Eakin, Laura Pereira, Lakshmi Charli-Joseph, J Mario \\ Siqueiros-García, Lichao Yang, Victoria Chengo, Dinesh \\ Abrol, Pravin Kushwaha, Edward Hackett, David Manuel- \\ Navarrete, Ritu Priya Mehrotra, Joanes Atela, Kennedy \\ Mbeva, Joel Onyango and Per Olsson
}

\section{Introduction: the overall ambition and approach of the 'Pathways' TKN}

The 'Pathways' transformative knowledge network started off by asking how transformations to sustainability are conceptualised across different theoretical and scholarly traditions, and how this can guide and influence the organisation of transdisciplinary research. We were interested in the role of transdisciplinary research involving new tools and practices and our role as researchers, in both understanding and helping to bring about the kinds of transformative change called for in the 2030 Agenda. In this final chapter we discuss these questions and consider what broader lessons can be drawn regarding the role of research - in particular research that is rooted within the social sciences but extends to incorporate other disciplinary and practice-based inputs - in these transformations.

As discussed in Chapters 1 and 2, we adopted a structured but flexible approach across hubs that allowed for transdisciplinary co-design, theoretical and methodological plurality and co-learning. Research teams in each hub worked with local stakeholders to identify and define the sustainability challenge (problem space) and to design and implement an associated research intervention over subsequent years. We worked with a small number of theoretical anchors (framings, systems and pathways) around which different hubs experimented and innovated. Individual hubs in fact adopted very different theoretical approaches and used the project to ask different questions about processes of transformation and the role of transdisciplinary action research within them (discussed in Chapter 3). However, there were some key elements that were common across all the hubs. They all made a concerted effort to bring out perspectives that might reveal alternative plural pathways, recognising and engaging with asymmetries in

DOI: $10.4324 / 9780429331930-16$ 
power relations, social differentiation in transformation processes and the politics entailed in understanding and fostering transformation processes.

The transformative knowledge network (TKN) adopted the notion of T-Labs as a methodological anchor (discussed in Chapter 2), building on the wider literature around participatory action research. Experimenting around the T-Labs concept, each of the hubs selected different social science and transdisciplinary methods (discussed in Chapter 4). Chapters 5-10 outlined the research and engagement processes undertaken across different hubs, in which various T-Labs focussed on conducting (or synthesising) research to understand the problem (all hubs), highlighting diverse framings about challenges and solutions (e.g. UK, Mexico, Argentina - see Chapter 11), where necessary helping to create a collective sense of the need for change (e.g. China, India), bridging across different views to build alliances (e.g. India, Kenya, Argentina), or helping to develop some more specific social innovation, prototype or experiment (e.g. Bioleft in Argentina, Gurgaon Water Forum in India).

Within the processes undertaken in each hub, we aimed to collect a minimal amount of comparable data around research and engagement activities (at T-Lab workshops 1 and 2) that was shared across the TKN through the mechanisms described in Chapter 2, and via bi-monthly online calls that continued beyond the lifetime of the project. As well as regular virtual interactions, moments of in-person reflection and exchange across all hubs took place at the outset of the TKN project (Buenos Aires, Argentina, April 2016), at the mid-point (Dundee, Scotland, September 2017), and towards the end (Nairobi, Kenya, October 2019) with representatives of some hubs meeting in person at other times. These in-person meetings were important for developing the friendship, trust and respect that was necessary to learn from diversity. They also offered some scope for in-depth discussion about comparative theory, methods and evaluation, however as discussed elsewhere (Ely et al 2020) time and resources were limited and insights have continued to emerge during the writing of this book.

The extent to which the original ambitions were realised differed across each of the hubs, and has been discussed in the earlier chapters. This chapter focusses on further insights that emerged from the processes of learning across disciplines, cultures and contexts. We organise our reflections on the basis of theoretical insights, methodological insights and learning about the co-learning/evaluation process. We offer tentative conclusions about "transformative pathways to sustainability" and lessons for future internationally networked, social science - led transdisciplinary research for sustainable development.

\section{Theoretical anchors and related insights}

As discussed in Chapter 3, the history of collaboration across the network provided us with a number of theoretical "anchors" that could be applied differently in each case. The role of the project was not to test these concepts (derived from work led from the global North) for their applicability in different contexts, but 
to explore their limitations and put forward alternatives grounded in the contexts in which the research was conducted:

- Systems - defined as "particular configurations of dynamic interacting social, technological and environmental elements" (Leach et al. 2010). The focus on some kind of fundamental system-wide change which will reach desired functions - concerned with enhancing environmental integrity and social justice - underpinned the design of the project and was an important aspect of our conception of transformation. However, the notion of "transformations" was not an anchor with a common definition across all hubs at the outset of the project. Chapter 3 (Table 3.1) discusses the objectives of each hub case study and the underlying theories of transformations that informed their work.

- Pathways - "the particular directions in which interacting social, technological and environmental systems co-evolve over time" (Leach et al. 2010). The concept notes that emerged from co-design workshops identified dominant and alternative pathways. Each of the hubs adopted different lenses through which these were characterised (associating them with concepts such as niches, paths, trajectories, mental models or windows of opportunity), as is evident from Chapters $5-10$. The work from the various hubs has led to emerging understandings of how pathways may be/become transformative.

- Framings - defined as "the different ways of understanding or representing a social, technological or natural system and its relevant environment. Among other aspects, this includes the ways system elements are bounded, characterized and prioritized, and meanings and normative values attached to each" (Leach et al. 2010). The co-design workshops and concept notes that emerged from them recognised different system framings, and their fundamental link to debates and challenges associated with sustainability. Chapter 11 considered processes of 're-framing' in transdisciplinary action research and how reframing (of system boundaries, what matters in a system and how, the nature of sustainability challenges and potential solutions) can underpin an appreciation of plural transformation pathways and the potential for realising them.

These anchors helped us to share findings and exchange conceptual interpretations between the hubs. They helped to inform our thinking together about transformations, including the identification and discussion of different approaches to transformations research (structural, systemic and enabling - also discussed in Chapter 3 and in Scoones et al. 2020). Building on these, we highlight examples where one or more of these approaches can form the basis of a transdisciplinary intervention within "solution-oriented" (Feola 2015) "transformational social science" (ISSC 2012).

Structural theories relate primarily to historical analyses of Western sociopolitical systems and draw on concepts such as Marx's (1995) class struggle, 
Gramsci's (1971) overturning of established social values/understandings or Polanyi's (1944) notion of the double movement to explain structural reconfigurations at the level of societies. While none of the hubs explicitly cited this literature at the outset of the project, some of the cases in this book point to the importance of structural factors, including those that are pertinent to locally specific conditions, whether of political economy or governance. An example would be the China case, which highlighted attention to workers and the disproportionate burden that green transformations had placed on them. Beyond the status of worker 'subjects' within the Chinese political context, the hukou "household registration" system in China, an important organising structure in the country's urbanisation process, is also relevant. The laid-off workers described in Chapter 8 were primarily land-lost peasants employed in private cement factories before the strict implementation of air-pollution controls. Formally, they had been reregistered as urban residents with urban hukou. However, they had only received basic education, were equipped with limited skills for the urban labour market, and had been forced to leave the agricultural sector (both physically and psychologically). Pollution control policies assumed that technical solutions could result in a more sustainable transformation, but little attention had been paid to the people who were carrying the costs of the resultant changes. Not only was this process of pain made invisible, but the omission of the re-registered urban hukou holders also allowed for a portrayal of China's green economic transition and poverty alleviation as a complete success.

Class was a central organising theme in the T-Lab work in India (Chapter 10), which was "conceptualised as a counter-hegemonic process of intervention". This highlighted intersectionalities between these traditional structural categories and other divisions around caste and gender (with urban-rural migration also playing an important role). Working across these identities, the Gurgaon Water Forum (GWF) (as a multi-stakeholder platform) attempted to build solidarity against the unfettered neoliberal forces shaping unsustainable and inequitable urban development. These elements of structural power comprise finance capital, real estate and IT, land owning castes in urban and peri-urban villages, lack of participation of poor and marginalised people, women workers in decision making, locals versus outsiders and religious and ethnic divides, and adverse integration of formal and informal (economy, urban settlements, planning, etc.).

Drawing on a long heritage, enabled by developments in computer modelling (see Scoones et al. 2007), systemic approaches to understanding transformation draw primarily on more recent theories of socio-technical or social-ecological systems. They are usually based on Cartesian, formal scientific understandings of system dynamics and struggle to accommodate indigenous and situated knowledges or alternative framings. At least in their earlier formulations, socio-technical systemic approaches insufficiently engaged with concepts of power (Meadowcroft 2009; Smith et al. 2010), but have increasingly started to incorporate these critiques into research on sustainability transitions (Avelino et al. 2016). As initially structured, approaches to transformation in the social-ecological literature only 
superficially addressed issues of agency, power and the implications of differential understandings of system dynamics (Brown 2013; Davidson 2010). There has been a significant effort in recent years to bridge more actor-centric and systemcentric approaches to understanding transformative change by highlighting the role of leadership in system-level change (Westley et al. 2013) and by engaging with differential meanings of resilience at different organisational levels and with different societal actors (West et al. 2014; Borie et al. 2019). Challenging framings within and beyond system boundaries, and fostering cognitive shifts towards local collective agency, played a role in a number of the cases.

In the UK hub, which focussed on agri-food systems at a local/regional level (Brighton and Hove), there was a clear recognition from the point of the codesign workshop that the notion of a self-contained agri-food system (scientifically defined in terms of stocks and flows) at this level was questionable, given the high proportion of external inputs of food and energy. While recognising the absence of a closed system, the social-ecological boundaries associated with the Brighton and Lewes Downs Biosphere provided more scope to engage with nearby growers. Towards the end of the project the research was framed around the Downland Estate (seen as a system providing multiple benefits to the city, beyond food, governed by the local authority). This system focus brought various stakeholders together, including more powerful actors with a financial framing and others prioritising biodiversity, access or local food systems, in a process of reimagining the potentials of the Estate for food production and other purposes.

In the work in Mexico (Chapter 9), chinamperos as well as residents of irregular settlements of Xochimilco had understandably partial perspectives on the problems facing Xochimilco, viewing the system from their own position, agendas and experiences. As a result, they put forward narratives that lacked an integrated systemic vision of the challenges of the wetland and their roles and influences within it. Changes in the Xochimilco Wetland were largely seen as driven by external forces; solutions were sought that were linear (rather than systemic) and to be applied to very specific needs. The T-Lab process and our work with chinamperos and activists concerned about the future of the Xochimilco wetland offered an opportunity to explore the more subjective (affective, experiential) nature of social-ecological systems and how they were perceived and delineated. We reframed the problem at hand by making visible the underlying web of meanings, values and aspirations of the livelihood practices in the region. The wetland "system" was thus reimagined as a product of deeply subjective and personal social relations and identities, rather than geographic attributes, ecological processes and abstract social structures. Through this process, the participants in the T-Lab process in Xochimilco articulated their own roles, relationships and activities in the system, rather than conceptualising the system as somehow external to themselves.

Enabling approaches differ greatly, depending on power relations between researchers and different actors. These approaches focus primarily on individual and collective capacities and agency in provoking transformation. Enabling 
approaches emphasise what O'Brien and Sygna identify as the "personal" sphere of transformation, in which internal reflection, shifts in individual values and ideas leads to deep, cognitive change and personal commitment to alternative trajectories of action (O’Brien and Synga 2013). Power is explicit in this approach to transformation, given that it emphasises the abilities of different actors, including those in the research team, to mobilise material resources, ideas, knowledge, or technology to instigate change (Scoones et al. 2015). And since power is relational - towards someone and about something/someone - "enabling" is always a social matter (Ahlborg \& Nightingale 2018). To some extent, all of our efforts were vested in this approach as those on the research teams engaged with others to explore alternative pathways to change and use our collective agency to pursue such change. This was often intertwined with processes of reframing values, systems, problems or solutions (as discussed in the previous chapter).

In the work in Mexico, our effort was concentrated on building the social scaffolding for the emergence of collective agency. Each participant carried their own social and political history and agenda, which in some cases conflicted with the understandings of other participants. In such a context, working towards building collective agency required acknowledging others as equals, valuable in their own right and as legitimate speakers. As facilitators, the research team had to create a sufficiently safe/"safe-enough" space (Raudsepp-Hearne et al. 2019) for everyone to open up and share their thoughts and feelings towards Xochimilco, regardless of their political views and social position in the community. For example, the research team worked with the other participants to identify what capacities and "powers" each had, and how these powers could be collaboratively mobilised to accomplish more than what any individual could accomplish alone (Ruizpalacios et al. 2019). The team could then see the nascent elements of collective agency emerging, largely through interpersonal trust and frank discussion of values and responsibilities.

The India case (Chapter 10) shows how mobilisation followed from convening groups that spanned different sectors, classes and interests as described above, recognising intersectionalities but trying to overcome them by developing collective practical understanding and collective agency. This was enabled through the process of building a "Network System of Solution Implementation" (NSSI) to evolve alongside the Gurgaon Water Forum on the ground and the Transdisciplinary Research Cluster on Sustainability Studies in the University. In a similar way, Bioleft (in the Argentinean case - Chapter 6) provided an institutional focus for enabling this collective agency - "bridging" across different framings and creating an alliance against the dominant patent-centric pathway. In both these (and other) cases, the resulting alliances enabled action and solution experimentation interspersed with critical reflection. Like the environmental movements described by Temper et al. (2018), these T-Labs adopted "values and ideologies that overtly reject hegemonic economic and political practices" and aimed to "confront and subvert hegemonic power relations". Enabling in this context meant assembling collectives that shared these values and found agency 
in developing the bridging innovation (Bioleft or Gurgaon Water Forum). This collective agency was further strengthened through broader mobilisation and follow-on projects that extended the scope of its work, as discussed later in the chapter.

Other examples across the TKN attempted to enable transformative pathways via broadening out (Stirling et al. 2007; Ely et al. 2013) the inputs to decisionmaking or action around different technologies. The Kenyan case (Chapter 7) illustrates the benefits of bringing different groups (with very different framings of energy futures) together to raise awareness of these tensions, and enhance mutual understanding. This represents a different approach to 'bridging', where alliances do not rely on shared opposition to an incumbent pathway, but rather seek to hybridise between established and novel approaches.

In other socio-cultural contexts, the enabling approach was less applicable. China's long history of a repressive authoritarian regime is intrinsically embedded into Chinese political and cultural practice, thus legitimising top-down decision-making and the dominance of the Party-state. People (e.g. the laid-off workers described in Chapter 8) naturally see the Party-state as rulers and themselves as subjects, especially when policies are associated with environmental protection. In this context, despite attempts to create a safe space and reframing sustainability problems and solutions, the enabling approach didn't work and success was limited.

To summarise, the experimental approaches detailed in each hub drew from the broad international body of literature on transformations and various concepts in transdisciplinary and action research domains (see Chapter 3) to pursue efforts towards transformation in their own specific context. This discussion cannot fully explore the disciplinary and cultural entanglements that led to the different strategies that were taken, but the notion of structural, systemic and enabling approaches provides a lens for comparison. Table 12.1 attempts to illustrate whether and how these were applied in each of the hubs.

The work also illustrates how these different approaches interacted with one another. In some of the cases structural perspectives were important in explaining stasis and undesirable outcomes, but also helped new alliances to envisage pathways to transformation. The role that enabling research can play in unsettling structural divisions (e.g. through convening broad networks and building alliances) was particularly evident, e.g. in the GWF, in which middle classes and migrant workers collaborated in opposition to the structural drivers of unplanned urban development. Future research that moves beyond those structural categories that are prominent in the (primarily European) literature to include non-Western categories and social orderings (caste, hukou) offers opportunities to further internationalise our understanding of transformations. Others among the cases presented here bolster the already expansive literature that adopts systemic perspectives to analyse contemporary transitions/transformations, injecting it with an awareness of power and positionality characteristic of 'enabling' approaches. In particular, they contribute new insights about the role of researchers 


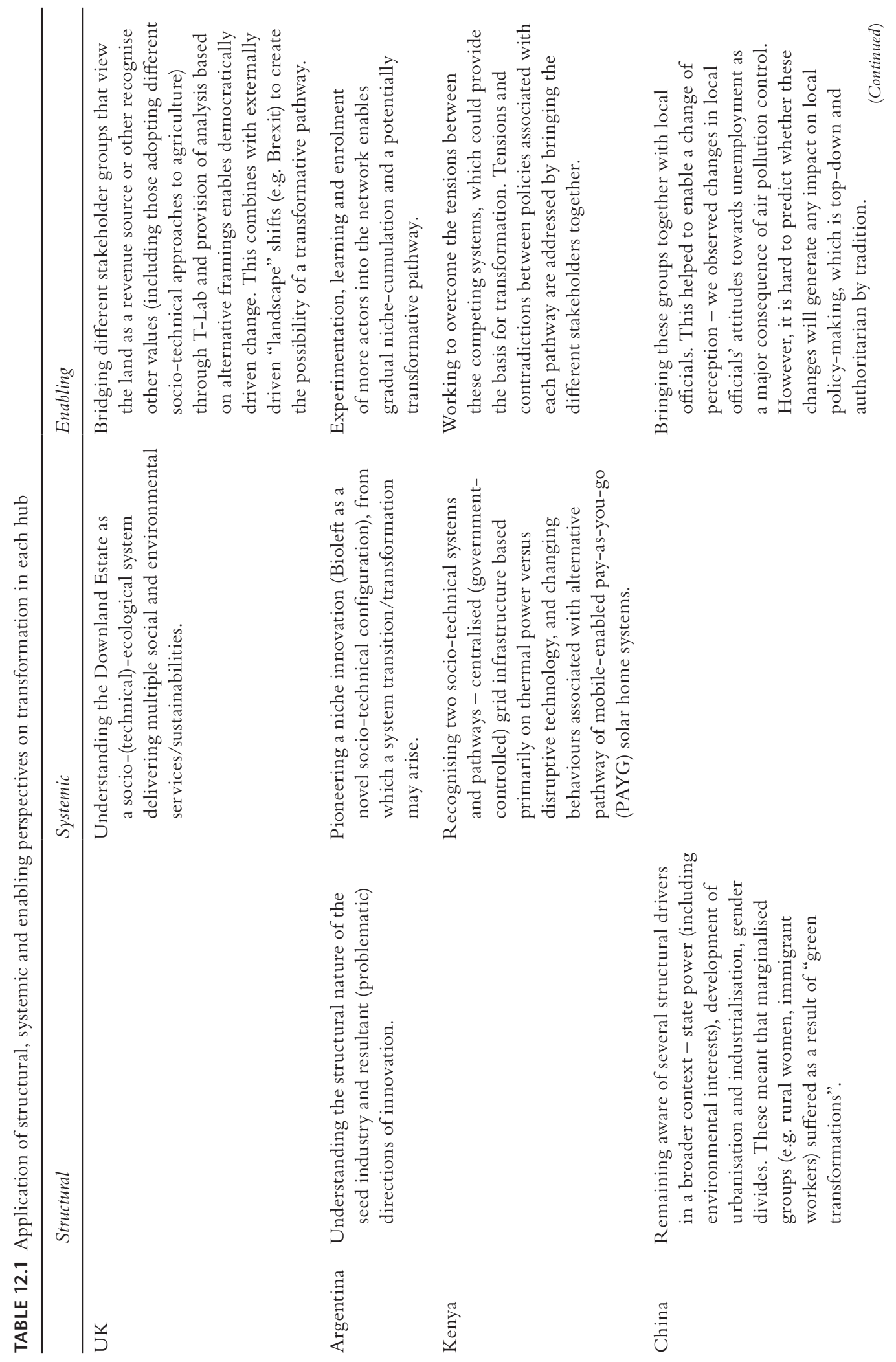






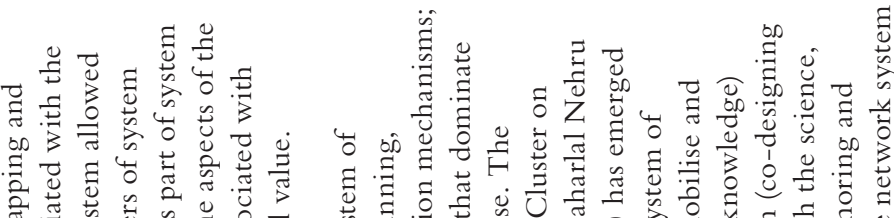

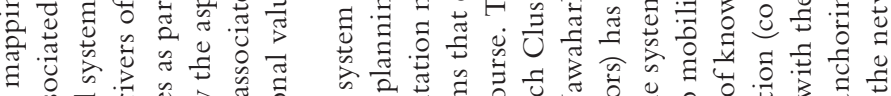




क人

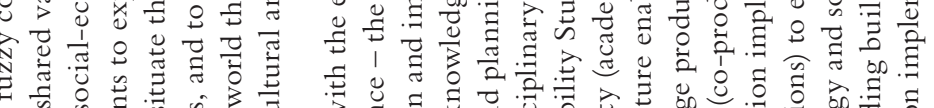

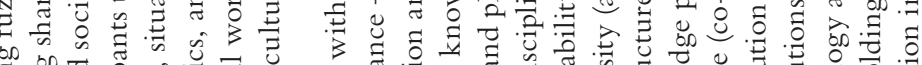

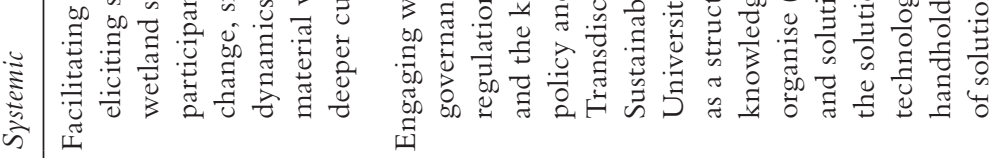

in bridging innovations and socio-technical configurations (niches, e.g. Bioleft), the importance of landscape changes (including exogenous events) during the transdisciplinary research process (e.g. citizen mobilisation against land sales) and an appreciation of different framings and re-framings of (socio-technical or social-ecological) systems, (several hubs, as discussed in Chapter 11). Perhaps more than either structural or systemic approaches, the T-Lab processes undertaken by the 'Pathways' TKN have helped to define 'enabling' approaches to transformations and what they look like in different contexts. The different enabling strategies adopted in each T-Lab (e.g. methods of monitoring network development/broadening out across aligned or non-aligned partners), the preliminary work to try to measure and characterise these strategies and insights about how they changed over time are discussed further in the next section.

\section{Transdisciplinary methods and related insights}

Chapter 2 described how the project adopted transformation laboratories (T-Labs) as a methodological anchor around which different hubs innovated and experimented. As discussed in detail in Chapter, 4, a T-Lab aims to:

- "Frame the challenge, find change-makers and strengthen their individual and joint capacities to more effectively address the challenge;

- Develop change strategies that test multiple solutions, which could help to solve the challenge;

- Create early prototypes of interventions and build momentum for action. In this case, prototypes could be new business models, services, or kinds of governance that fundamentally change human-environmental interactions and contribute to changes for a better future".

T-Labs, as explored in this volume, opened up spaces for productive collaboration and interaction between diverse stakeholders, drawing on a range of participatory research methods and engagement strategies to help contribute to sustainability transformations. Seen as a process rather than a methodology, T-Labs have been used in diverse ways to create the kinds of "transformative spaces" in which experimentation with new configurations of social-ecological systems, crucial for transformation, can occur (Pereira et al. 2018; van Zwanenberg et al. 2018; Marshall et al. 2018; Charli-Joseph et al. 2018). "Transformative spaces" has emerged as a concept from diverse cases in the Global South that emphasise the complex realities of what transformation entails from more bottom-up approaches. It is a reflection of navigating histories and differences that have been reinforced through a largely colonial project within which Western extractive science remains embedded (Pereira et al. 2020). By opening up and giving space to interpret the idea of transformative change from the perspective of a specific place (rather than a "lab") and build theory and understanding from experiential knowledge (rather than privileging the scientific), an attempt is 
made to reconfigure the power dynamics away from the researcher and towards the participants. Part of this involves the need to strike a balance between 'safe spaces' (in which marginalised groups can feel confident to voice their concerns) and 'safe-enough' spaces for transformation (which leave room for tension and discomfort, e.g. where dominant narratives are challenged). The operational realities of achieving this balance in T-Labs are extremely context-specific.

T-Labs as transformative spaces are conceived as open-ended processes and developed in this way, however, how to do so remains a difficult area for the action research/research-practice interface. We encountered various problems well-known to those familiar to action research - our research aimed to ensure that marginalised voices were included, however we could not assume that any such partners would have time to engage, and needed to avoid setting expectations of change that we had relatively little agency to galvanise, given the timeframe over which transformations can emerge and the limited time and resources available to the project. In all cases, T-Lab participants were engaging largely on the basis of shared normative commitments and continue to do so in various hubs at the time of writing this chapter, two years after the official end of the project.

Under these circumstances, it was important to consider the roles played by academic researchers (and 'research' more generally) alongside other actors in transformations, over the short and longer term. There are different conceptualisations of the role of researchers in transdisciplinary endeavours, particularly those that are more about process than knowledge production. Witmayer and Shäpke (2014) posit that researchers can play different roles over the course of transdisciplinary research initiatives, and different members of a research team can also serve distinct functions. They identify five such research team roles: as change agent, as knowledge broker, as reflective scientist, as self-reflexive scientist and as process facilitator. In more traditional research projects, researchers often are positioned exclusively as reflective scientists, collecting and analysing data as an external observer, while the other roles are typically more prominent in transdisciplinary work. Across our projects, our research teams combined roles in different ways according to the circumstances and demands of actors with whom we were engaging. Furthermore, our multiple roles changed and evolved as the T-Labs' activities responded to changing conditions.

While T-Labs (as described in Chapter 4) may rely on "participants who are willing to take a leading role" in transformation, this "change agent" role was rarely borne by researchers. In Mexico, e.g. the team served as facilitators and conveners, and brokers of knowledge, but refrained from actively directing the assembled group towards a specific previously defined end, in order to let the agency for change emerge from the convened group as a whole. Self-reflection was a critical part of the project, as the research team pushed back on demands that they provide specific solution pathways yet also recognised that they too had resources and capacities to offer to the group as part of collective efforts towards change. As the Xochimilco T-Lab work developed beyond the lifespan of the project, researchers and other participants established an NGO - Umbela 
Transformaciones Sostenibles - inspired by the desire to take forward the kinds of engaged and experimental forms of action research that had been pioneered in the TKN, and to create the institutional form that would best enable this collective action. In India, the Gurgaon Water Forum continued to attract partners, secure additional funding and implement water projects after the formal International Science Council (ISC) grant came to an end, illustrating the longevity and continuing evolution of the NSSI. The GWF was able to initiate the process of institutionalisation of emerging practices and processes of knowledge co-production.

The changing role of the researchers co-evolved with the changing roles (and make-up) of other T-Lab participants. The design of the project (described in Chapter 2) allowed us to trace how engagement with aligned/non-aligned or more/less powerful actors (as described in Marin et al. 2016) changed over time. While attempts to quantify subjective measures of alignment and power were not seen as appropriate by all hub teams, even qualitative reflection about "alignment" yielded interesting insights. Different strategies were identifiable, e.g. in comparison between the UK (Chapter 5) and Argentina (Chapter 6) cases. From the point of the co-design workshop to T-Lab workshop 2, we can see that the UK hub broadened out from a more aligned to a less aligned T-Lab network. It began by engaging primarily with civil society actors, but increasing project momentum meant that the team - acting as knowledge brokers - were able to engage representatives of statutory bodies and the local authority at the second T-Lab workshop. The process facilitator role ended here, but, along with a number of other processes, the T-Lab activities foreshadowed a formal consultation initiated by Brighton and Hove City Council in 2020, that aimed to set out a vision for the future of the City Downland Estate. Here, some members of the research team continued to be knowledge brokers, but engaged as citizens rather than any of the roles described by Witmayer and Shäpke.

The Argentinean hub began with a broader engagement approach (including with non-aligned actors), but later played a change agent role in collaboration with the narrower, aligned network involved in Bioleft (while still engaging with non-aligned, powerful actors through indirect means). Chapter 6 illustrates how the involvement of various groups, aligned in opposition to the dominant pathway but not necessarily in their vision for the future, led to continuous diversity and negotiation of choices, with expectations often generated by particular actions and pathways, rather than an orderly adoption of plans informed by a settled consensus. This came alongside the team's conscious decision to "relinquish some degree of power" (Chapter 6).

Across the hubs, we discussed these changing roles and the questions posed by such open-ended research. Pereira et al. (2019) point to "ethical dilemmas associated with creating a transformative space", which were undoubtedly encountered in many of the hubs, despite the differences in approach that they followed. In all our work, the ethical issues entailed in our interventions were also prominent: who decides what the scope and boundaries of the process should 
be? Who decides who participates and why? What might be possible unanticipated adverse consequences of implementing a T-Lab process in specific political, economic and social moments? What might be the potential for harm, and who is responsible? In all instances, deliberatively convening a space with the aim of transformation is an act that requires ethical reflection, especially when marginalised voices are included (Pereira et al. 2020). Before embarking on a T-Lab process, expectations need to be managed; and what convening the space could mean for the participants who engage, especially for those who may already be vulnerable, needs to be deliberated on and transparently communicated to all those who take part. The acknowledgement of uncertainty in the process also has implications for how to apply for ethical clearance from universities that are generally less well-equipped to assess such collaborative, messy transformative processes. These ethical issues played out differently in different contexts (which are themselves changing - see, e.g. Yang and Walker 2020). More research and experience would enable a learning community to better ascertain and assess the ethical implications of T-Lab processes and perhaps establish a set of guidelines for setting up such interventions.

Transdisciplinary research and the alliances of actors that it enables are instrumental in navigating the politics of knowledge, and can be influential in addressing the structural biases in knowledge systems that cause cognitive lock-in and resist transformative change (Marshall et al. 2018). These roles in challenging cognitive lock-in, understanding resistance to change and working with diverse stakeholders to reframe elements of sustainability challenges in order to reveal plural pathways for transformation were apparent in all cases. However, the navigation of these multiple roles was a struggle that has been felt across all the cases as teams have attempted to balance their normative commitments, existing and emerging alliances and multiple institutional pressures at local, national and international levels. The TKN's meetings have enabled a sharing of lessons, understanding and support across the hubs about the multiple, changing roles of researchers in these sort of transdisciplinary research processes.

\section{Learning from, through and about transdisciplinary research for transformations}

The project aimed to better understand the role transdisciplinary research can play in transformations to sustainability. Accompanying the move from analysis to action was our desire to build understanding of the causal relationships between the research processes we were facilitating and emergent transformational outcomes, or movement towards them. This understanding had to be built through the specificity of the problem areas and the particular stakeholders engaged in each hub context. The theoretical conceptions of transformations applied in the hubs differed (Table 3.1) and were used to select appropriate methods for the T-Labs (Chapters 4-10), which meant that the interventions themselves also necessarily differed greatly. 
As well as a high level of diversity across the hubs, the interventions were also built with stakeholders, implying that we could not know or specify what would be done in advance. This emergent and participatory design made it challenging to determine at the outset the specific indicators of intended impact, and so it was not possible to develop a baseline against which to later measure the effects of interventions. In addition, the transformative change we were aiming to evaluate was/is dynamic and unpredictable, and the timeframe long. It was, therefore, highly unlikely that end impact, even if it were to eventually occur, would be discernible during the project lifetime or in the years following (e.g. through to the publication of this volume). Application of simple pre- and post-evaluation methods to measure the net effect of research as an intervention was simply not appropriate.

Our response to the combination of internal diversity and unpredictability was application of complexity-aware evaluation approaches (e.g. Douthwaite et al. 2017; Patton 2010; Apgar et al. 2020). Such approaches argue for regular revisiting of assumptions about how change is unfolding (though real time feedback loops) coupled with the use of goal independent evaluations that capture change as it emerges rather than through tracking predetermined indicators. Evaluating emergent design of interventions to contribute to emergent impact pathways requires, fundamentally, that implementers learn as they go and focus on understanding how change unfolds rather than measuring net effect.

In practice the approach was operationalised through purposefully building moments for critical and evaluative reflection at two levels - (i) within the participatory research processes in each T-Lab and hub and (ii) across them. Reflection within the different hub contexts provided insights in terms of single-loop learning (instrumental learning through theoretically informed action). For example, Agency Network Analysis and Q method were used to explore quantitative differences in perceptions of T-Lab participants as the Xochimilco T-Lab evolved. Alongside qualitative evidence of increased empathy, the theory of change saw these as contributing to collective agency - "one important ingredient towards system transformation" (Chapter 9).

Moments of exchange and reflection within hubs (across academic and nonacademic stakeholders) and across teams from other hubs in the network supported double-loop learning (questioning the underlying theories in order to improve them). Double-loop learning can be seen in the shifts in theory of change and strategy in Argentina, from policy engagement towards the action-oriented establishment of Bioleft. Double-loop learning in India involved transdisciplinary co-design with trade unions (Centre of Indian Trade Unions) and science and technology-based voluntary organisations (Society for Geo-informatics), enabling them to change their practice in ways that were more consistent with the longer term interests of working people. Our periodic efforts to report our activities and evolving thinking to each other in the form of blog posts, virtual discussions across multiple time-zones and in-person project meetings provided opportunities to step outside our efforts and take a critical look at the rationales 
and assumptions we held in each of our separate efforts. Three moments shown in Table 12.2 created opportunities to make explicit and reflect in person upon the assumptions we held about how the T-Lab interventions were supporting process of change, and so to bring together our theoretical work on transformations with our empirical and experiential learning from implementation.

Embedding evaluative thinking into our collaborative research processes within and across hubs enabled learning, yet it also made it difficult to create the space and process to examine causal inference around how change was unfolding as a result of the T-Lab interventions. Opening up space for critically examining evidence of causal inference from within the change process is challenging. Indeed, normative, change-seeking participatory researchers often struggle to evaluate their contribution to change because they are so directly implicated in it. Working across different disciplines and contexts aided the process of reflection by drawing attention to differences in framings and assumptions underlying our efforts, but causality remained elusive.

Our experience aligns with emerging evidence across evaluations of complex research for development programmes (Apgar \& Douthwaite, forthcoming; Apgar et al. 2020) on the time it takes, and explicit effort required to refine theories of change through the research process itself. When causal pathways are long and unpredictable, and when the research is participatory in nature, any initial definition of theories of change should be thought of as 'plausible promises' providing a broad direction of travel without prescribing or constraining action. In our case, the initial participatory impact pathways analysis (PIPA) processes enabled an early and prospective view of opportunities for supporting outcomes through contributing to changes in the knowledge, attitudes and practices of specific stakeholders (e.g. shifting demand towards local food in Brighton and Hove). This was helpful to orient strategies for engagement, but as noted in Chapters 5-10, as implementation evolved in context, the teams refined their strategies and so too their assumptions about how they might influence change. It was not till the later stages of the process, through learning and building trust with

TABLE 12.2 Reflective moments and their contribution to evaluation of T-Labs

\begin{tabular}{|c|c|}
\hline Reflective moment & Contribution to evaluation of $T$-Labs \\
\hline $\begin{array}{l}\text { Inception workshop April } 2016 \\
\text { Buenos Aires }\end{array}$ & $\begin{array}{l}\text { Informed by co-design workshops in each hub, } \\
\text { adapted PIPA processes provided a prospective } \\
\text { view of how the T-Lab might influence networks } \\
\text { and stakeholders in the system - fed into T-Lab } 1 \\
\text { designs (shared between some paired hubs). }\end{array}$ \\
\hline $\begin{array}{l}\text { T-Lab reflection workshop } \\
\text { September 2017, Dundee }\end{array}$ & $\begin{array}{l}\text { Consolidation of early insights and deeper reflection } \\
\text { on theories of change, building on initial PIPA - } \\
\text { informed some T-Lab } 2 \text { activities. }\end{array}$ \\
\hline $\begin{array}{l}\text { Final workshop October 2018, } \\
\text { Nairobi }\end{array}$ & $\begin{array}{l}\text { Reflection on impact and researcher experience as } \\
\text { change agent. }\end{array}$ \\
\hline
\end{tabular}


stakeholders, that greater specificity on potential causal links between research and outcomes was revealed. Within the growing use of contribution analysis (Ton et al. 2018; Mayne 2008) and realist evaluation (Pawson \& Tilly 2001; Punton \& Vogel 2020) employed in evaluating research as an intervention, evaluators are grappling with how to identify the 'right level' of theory of change and at what scale along emerging pathways, to be able to investigate causal claims. In reality, it is often not till the end of the research endeavour that we have sufficient understanding of what is even worth evaluating.

An associated challenge to understanding causal inference was the temporality of the change process. In the project timeframe it was not possible to collect robust, observable evidence of transformative change, and so naturally researchers were focussed more on deepening and further opening up opportunities for change as they saw them emerge. Evaluation efforts were therefore proportionate to the scale of the project activities and the resources available. This balance differed across hubs, but in all cases the available time and resources were stretched between commitments to opening up hub-specific transformations and commitments to the overall international TKN-based evaluation/learning enterprise. Individual, institutional, disciplinary and national political cultures all shaped the ways in which we navigated these tensions (reflecting the observations in Chapter 3).

Beyond these instrumental and substantive learning efforts, the project sought triple-loop insights of a "learning about learning" nature (see Argyris \& Schön 1996; Tschakert and Dietrich 2010), in this case learning about the learning and collaboration process (Hackett and Eakin 2015 - see Chapter 2). Through insights into transformative spaces including those above, and an examination of the effectiveness of our collaboration (Ely et al. 2020), we have to some extent realised these ambitions. The writing of this volume offers, in itself, a renewed opportunity for this learning about learning, as we evaluate what aspects of the activities we engaged in, and which outcomes we've seen, embody the transformations we are ultimately interested in mobilising, participating in and realising. We are learning from the ways in which different hubs explored specific aspects of what we might understand as 'transformative pathways to sustainability'.

\section{Transformative pathways to sustainability}

Taking the above analysis further allows us to explore the notion of "transformative pathways to sustainability", one of the original aims of the project (and the book), as a development of the pathways approach. In our search for a conceptual contribution, we have not articulated an overarching theory of transformative pathways to sustainability, but this should not be seen as a failure. To the contrary, we learnt that there is unlikely to be a single theory of change that works across all disciplines, cultures and contexts, and that the pursuit of such a theory may say more about academic ambitions than it does about the process of change. Instead we draw from the work in different hubs to point to various findings that resonate with, complement or challenge the pathways literature to date. 
Pathways are "the particular directions in which interacting social, technological and environmental systems co-evolve over time", but what makes them "transformative" (able to bring about profound change)? What determines the extent to which these profound reconfigurations of interacting social, technological and environmental systems tend towards "sustainability"? What makes them durable or resilient? And what are the roles of research and practice, and the structures of real-world experimentation in helping to bring these about?

In answering such questions, we expanded upon the theoretical "anchors" reframing, systems-thinking, pathways - discussed above and in the previous chapter. More work is required to explore how these inevitably play roles of differential prominence according to the political, institutional and social conditions where T-Labs are implemented. But elements of the work presented here offer a foundation upon which to build in the future. These could be further examined in future collaborations that apply some of the lessons learnt from the 'Pathways' TKN to new cases, or build upon the rich body of knowledge that has emerged from the network so far.

The structural, systemic and enabling approaches to transformations discussed above can be viewed through the lens of pathways, with each prioritising particular actors, forces, relations or causal mechanisms in their explanation of transformative change. The enabling approach that was common to each of the hubs focussed on fostering transformative agency at the level of individual actors but also across T-Lab networks. Whether through intellectual or affective engagement, several actors witnessed a reframing of sustainability challenges and their capacities to address them. But these became more potent when combined with new relationships and partnerships, reflecting earlier work that has suggested "transformative pathways will often involve transformative alliances among different actors - governments, businesses, academia, and citizens" (Leach et al. 2018). In both these individual and collective senses, the T-Labs played an important role.

While our approaches, activities and the contexts of our separate initiatives differed greatly, we recognise collectively the value of the figurative, social and physical "space" that the T-Labs provided. In each case, the T-Labs simultaneously were providing activities that were directly engaging with, while also providing the reflexive spaces to separate from, ongoing processes of social, ecological and technological transformation. The changing nature of the T-Labs, including the stakeholder categories, alignment and power of the actors involved, and their shifting roles, represents an important 'transformative' aspect of the pathways under construction. The evolving activities, from convening to "establishing a collective sense of the need for change", through to prototyping, developing and testing innovations, represent a microcosm of the kinds of transformation required at the societal level. In some hubs (e.g. Argentina) this evolution was seen as cyclical and iterative. The T-Labs provided a space for both thinking and action, with each informing the other and contributing 
to innovation and enhanced collective agency. As explained in Chapter 6, "the ability to demonstrate how an initiative works, even if only as a prototype, is a critical source of agency".

The transformative spaces offered by T-Labs thus allowed for the sharing and combination of knowledge and resources (with a view to innovation) in ways that were otherwise rare. At least in some cases, they fostered collaborative imagination and inclusive (and accountable) experimentation. Each of these experiences offers lessons for the design and implementation of Labs as a contribution to transformative pathways in specific contexts. Transformative pathways at societal scales might be characterised by similar cultures of experimentation, drawing on broad knowledge/capabilities and open-ended, non-hierarchical collaborations.

We also recognise the complexity of social transformation and innovation. What might constitute significant change must also be understood in relation to place, culture and political-economic conditions. Whether at the level of individuals, T-Labs or wider processes of transformation - our responsibilities as researchers led us to reflect as much on changes in ourselves as in the systems in which we were intervening. We were required to re-think the role of science and to interrogate the politics of knowledge within social change at a personal level. Transformations research, like the process of co-design (Moser 2016) can be "an agent of transformation itself" and an agent of self-transformation. A number of members of the Pathways network continue to discuss these issues as an aspect of triple-loop learning.

The limited timeframe of the project required attention to what would come afterwards, given the "monthly to decadal" nature of sustainability impacts (Norström et al. 2020). In the Mexico case, T-Labs could be seen as a kind of "cocoon" that participants created to protect themselves while exploring transformation, after which - at some point - it opened up to reconnect to the wider system. With this in mind, the Mexican team were cautious both in the selection of participants and in where interventions would take place (at the university, chinampas, etc.). In the India hub, the NSSI structure was designed to realise a minimum level of political and academic rigour that ensured the GWF did not collapse after the project was over. In all these cases, collective agency may not lead immediately to wider change, but creates a resource - a latent structure or propensity to collaborate - that may be able to respond to future windows of opportunity or moments of need. The T-Lab relationships that aided collaboration following the earthquake in Mexico (Ruizpalacios et al. 2018), or those that have enabled a more coordinated response to the agri-food changes underway in the UK (Ely and Wach 2018), are examples. The arrival of the Covid-19 pandemic (between the completion of the previous chapters and the drafting of this one) posed challenges in every hub, and in many cases, the relationships and networks that had emerged from the previous five years' work supported the immediate responses seen in hubs. Transformative pathways emerging from local levels will play an important role in resetting the 2030 Agenda, alongside top-down efforts 
(exemplified by the United Nation's call for governments to use the opportunity of Covid to 'build back better' - see UN 2020).

\section{Lessons for internationally networked research on transformations into the future}

As a contribution to Future Earth, the Transformations to Sustainability Programme represents one of the few social science-led initiatives applying truly international research effort to the SDGs and wider sustainability challenges. The important leadership of the International Social Science Council (ISSC) in co-ordinating the programme since its genesis should be acknowledged. The role of social science is crucial in understanding - and intervening in - social transformations for sustainability, and this needs to be borne in mind in the design of future research programmes. It is especially important following the merger in 2018 with the traditionally more natural science-led International Council for Scientific Unions (ICSU) to form the International Science Council (ISC).

The findings in this book offer lessons for integrating social and natural sciences with other non-disciplinary specialisms across international networks that are engaging with locally specific sustainability challenges. As is evident from the discussions above and in preceding chapters, the design and implementation of the project tried to balance trade-offs between various objectives at the hub and TKN levels. Moser (2016) described similar phenomena when analysing co-design across a broad range of projects in the same Transformations to Sustainability programme - trade-offs and tensions "between scientific rigor and an open, bottom-up design; codified data and the non-reductive work with parallel narratives; an emphasis on the advancement of science (and theory) for its own sake and the instrumental character of research with practical benefits in specific grounded realities; the immediate needs and wishes of actors and the long-term focus on a more transformative agenda; work at multiple scales with diverse geographies and site-specificity; and, finally, between funder requirements involving multiple innovations creating challenges around feasibility and cost (the opportunity, monetary and environmental costs of global collaboration) and the familiarity and ease of collaboration following more familiar standard procedures". We feel that there is more to learn from our experiences of trying to reconcile these tensions, and from the project's broader strengths and limitations. In considering these, we hope that the triple-loop learning enabled by the Pathways TKN may improve the learning process in future networked transdisciplinary research projects.

A group discussion of "what worked" and "what didn't work", undertaken at the final TKN project workshop in Kenya in 2018, highlighted the flexible approach as a strength citing "respect, learning from diversity across hubs"; "autonomy in the hubs (freedom to find what works for them)"; "legitimate input from the global South" as positives of this approach. At the same time, theoretical and methodological exchanges were suggested to have been limited by the fact 
that different hubs approached methods very differently. We feel that the use of theoretical and methodological anchors helped us to strike a good balance, but regret that we did not take longer to interrogate these concepts at the outset. Likewise, a structured approach to collaboration that provided a common schedule of research and data collection but allowed hubs to diverge (see Chapter 2) is a pragmatic adaptation that future projects can learn from.

Incorporating online and in-person communication and exchanges into the design of the project was important, however the practical ways in which interactions emerged also showed strengths and weaknesses. The discussion in Kenya, which included senior and junior team members from all hubs, found that the "inception workshop for getting to know each other made a good base - the culture and tone of the project set from the start", mentioned that "having meetings at points throughout the project was great" and stressed the importance of "friendships and networking". Without these enduring friendships, it is highly unlikely that the bi-monthly teleconferences would have continued on so long beyond the end of the project, or that the completion of this book would have been possible. On the subject of virtual communications like the teleconferences, SharePoint, etc., the discussion noted the "technological challenges of virtual, de-centralised information exchange" and, despite experimenting with numerous tools over the time period of the project, concluded that all platforms were "problematic or limited". More broadly, the approach to pairing hubs did not always work due to different approaches/lack of continuity of engagement/"chemistry" and one table thought that "South-South interactions were not fully made use of". This may have been a consequence of time and resources, which were found to be "a constraint to interactions, reflection and learning". Nevertheless, the discussion commended the "commitment from hubs despite challenges faced in their different contexts of work". This has been especially pertinent during 2020-21, when regular interactions continued despite the end of the project and the urgent Covid-19-related challenges being faced by all hubs.

For some, the transdisciplinary nature of the project was their first experience of such work, and the discussion celebrated "knowledge generation and the move from their research to action and impact". Starting with an intention to engage in and be part of a change process offers for some sustainability researchers a radically different positionality which comes with both opportunities and challenges. Reflecting the discussions above, measuring impact was seen as a weakness by some "because of a lack of clear definition of what impact is", although this view was not widely held. More broadly, the TKN members were positive about "establishing a global movement in sustainability, transformative research and action". This movement, in which the Pathways TKN plays a small part, is building momentum and increasingly drawing upon more diverse knowledge and practices. Our TKN has seen the completion of PhDs by students across three hubs (Mexico, Argentina and China) - these and other early career researchers are leading innovators in transdisciplinary research methods and approaches. Incentive structures must recognise this leadership and help to build 
this momentum. The urgent need to transform science and research further, ensuring that investments deliver on shared global challenges (by bringing about changes at multiple levels) has never been greater.

The discussion in Nairobi also reflected upon the long time-scales over which these changes sometimes take place, and TKN members lamented that "opportunities for follow-on funding have not been successful" and "stakeholders in hubs expect continued support but resources are no longer available". At the time of writing (December 2020), at least three hubs (Argentina, India, Mexico) have been successful in obtaining funds to continue or develop their T-Lab work further, and others (UK, Kenya, China) have seen their engagement continue in other ways. Through Bioleft, the open-source seeds initiative that was launched through the project, a new network of researchers, growers and policy actors is exploring potentially transformative ideas for Argentina's seed system (also initiating collaborative work on maize and tomatoes with the Mexican team). In India, the Gurgaon Water Forum set up during the project continues to be a venue for deliberation on the city's infrastructure. In Mexico, the work in Xochimilco has generated a set of innovations and ideas on research and appraisal methods, which is being taken forward into new initiatives in late 2020 and 2021 that seek to deepen alliances by creating an NGO that institutionalises the collaboration between academic and non-academic T-Lab partners. In the UK, the project outputs are (alongside other resources) feeding into a broad process to develop a "vision for how our downland could be managed over the next 100 years” (BHCC 2020). In Kenya, the new 'African Research \& Impact Network' hosted by the African Centre for Technology Studies (ACTS) is taking forward discussions on 'inclusive energy', including through a series of online discussions. The China work in Hebei is being built upon by work on multiple dimensions of poverty, including those linked to green transformations (which have been studied in Datong Coalfield, Shanxi).

Multi-million dollar bids to continue and extend upon the collaboration across the TKN (submitted to UK research councils) have been unsuccessful. This is unfortunate because change of any such scale and depth requires persistence. However, collaborative work involving the UK, India hub and collaborators in China is being funded by the British Academy and the Argentina, UK and Africa hubs are being supported by a new grant from the International Development Research Centre (IDRC). Notwithstanding these encouraging trends, the points raised in the discussion regarding funding highlight important questions for the ISC, Future Earth and other organisations wishing to support networked transdisciplinary research towards the transformative agenda of the Sustainable Development Goals.

When addressing SDG-type challenges, we enter a hybrid space of research and development impact. The sustainability space calls for a focus both on the production of knowledge (often with a focus on actionable or policy-oriented knowledge) and generation of evidence, while also thinking about whether and how we make a contribution to ultimate development outcomes - the desired 
transformational outcome. As one of the first international projects that has generated evidence about how to accelerate learning and change in this hybrid space, the experience of the TKN in this regard sparked a number of insights that are relevant for the funding, design, implementation and evaluation of future programmes.

\section{Funding}

- In general, the funding provided by the T2S programme (now in its second phase) provided better opportunities for new forms of transdisciplinary experimentation than those available in many national or international contexts. More funding of this type, with mechanisms to ensure continued support should be encouraged.

- We would recommend that research funders collaborate with other types of donors (private foundations, impact investors) to improve the ecosystem of support for the kinds of experiments and innovations that emerged from the Pathways TKN.

- Various elements of the T2S programme (e.g. grants led or co-led from a low- or low-middle-income country, emphasis on early career researchers) represent best practice in the field. Resources need to be allocated to building long-term capacity in project management as well as research.

- Bureaucratic challenges of these types of programmes should not be underestimated. International efforts by the Belmont Forum and others to develop infrastructures that address these and reduce transaction costs are of longterm benefit to all.

- Flexibility in contracting modalities should be sought to remove bureaucratic obstacles to learning in real time. Many of the lessons (including those summarised below) require leaders to embrace ambiguity and take risks which are in tension with incentives to communicate simple messages about measurable impact achieved.

\section{Design}

- Programme design that incorporates and incentivises interaction across international teams (as in the T2S programme) is to be welcomed. Providing adequate resources to enable face-to-face interaction in the global South is a long-term requirement if ownership is to be shared and power imbalances challenged.

- Rather than aiming solely for academic outputs (e.g. publications) programme design should recognise the enabling elements of transformations, including collective agency, alliances and their role in resisting/destabilising unsustainable incumbents as well as generating alternatives.

- Attention to structural, systemic and enabling approaches towards transformations may be more appropriate in different contexts and at different 
times. This book illustrates how programme design may incorporate these as feasible contributions to transformative pathways.

\section{Implementation}

- Internationally networked, transdisciplinary research is not well-served by conventional ethical norms (which are often based on "best practice" in Western medical settings). While these play an important role they can hinder transformations and may not be able to recognise the potential risks inherent in actively seeking to co-produce solutions for transformative change.

- Implementation of transdisciplinary research requires more flexibility, addressing changes in knowledge, networks and contextual developments. In this regard, reflexive use of theory of change can help to reconcile tensions between funder and researcher logics.

\section{Evaluation and learning}

- Research in the field of transformations to sustainability is not used to evaluating its impact, so there is lots of room for methodological innovation. Some of the work presented here (e.g. India, Mexico and Argentina hubs) offers lessons for how to measure change in networks and enrolment, but these represent a small component of 'transformations'.

- Much of the work in this area needs a broadening of evaluation designs to more theory-based evaluation research that is embedded in how transdisciplinary researchers theorise and learn from their practice. This also needs the funding world to move away from simple, linear and attribution focussed evaluation design. The challenge will be to establish an appropriate balance between catalysing and sustaining change, on the one hand, and studying and evaluating the process, on the other.

- It is important to acknowledge recent progress in supporting design and evaluation of research for development impact, illustrated by IDRC RQ+ (Ofir et al. 2016; Lebel and McLean 2018) and Global Challenges Research Fund (GCRF) foundation evaluation design (Barr et al 2018), which provide some early evidence of a broadening of evaluation approaches and an emphasis on learning. The latter requires nested use of theory of change across scales, e.g. in large international projects such as the GCRF Interdisciplinary Hubs (UKRI 2019).

- Particularly encouraging developments include the reflexive use of theory of change that is promoted through funder guidance to grant holders - this requires grant holders to revisit and update theories of change based on the evidence and learning generated within their projects. This call for adaptive management (see also Ramalingan et al. 2019; Prieto Martin et al. 2020) is in line with much of the learning shared in this book. Deepening impactful 
practices will require the whole ecosystem of transdisciplinary research networks to focus on how it enables or hinders learning and reflexivity.

We offer these concluding insights to donors, academics, policy-makers and civilsociety organisations who support, develop, implement and evaluate transdisciplinary work on transformations to sustainability. Many of the recommendations above are easily articulated in the pages of a book. However, they are more difficult to action, given the political and institutional structures in which current transdisciplinary sustainability science is embedded. Alongside action-oriented, engaged scientific enquiry and activism, efforts to challenge the power relations that act as a barrier to sustainability need to be seen as an intrinsic element of transformations research. We hope that this book can be seen as a contribution to this ongoing work.

\section{References}

Ahlborg, H., \& Nightingale, A.J. (2018) Theorizing power in political ecology: the where of power in resource governance projects. Journal of Political Ecology 25(1): 381-401. doi: 10.2458/v25i1.22804.

Apgar, M., Snijder, M., Kakri, S., MacLeod, S., Paul, S., Sambo, A., and Ton, G. (2020) Evaluating CLARISSA: Innovation driven by a participatory learning agenda, CLARISSA Working Paper 2, Brighton: IDS.

Apgar, M., Hernandez, K., \& Ton, G. (2020) Contribution analysis for adaptive management. ODI Briefing Note.

Apgar, M., \& Douthwaite, B. (forthcoming) Participatory theory of change: Reflecting on multiple views of how change happens. In SAGE Handbook of Participatory Research.

Argyris, C., \& Schön, D.A. (1996) Organizational learning II: Theory, method, and practice. Redwood City, CA, USA: Addison-Wesley.

Avelino, F., Grin, J., Pel, B., \& Jhagroe, S. (2016) The politics of sustainability transitions. Journal of Environmental Policy \& Planning, 18(5): 557-567. doi: 10.1080/1523908X.2016.1216782.

Barr, J., Simmonds, P., Bryan, B., \& Vogel, I. (2018) Inception Report: GCRF evaluation Foundation stage, Technopolis Group \& Itad. https://assets.publishing.service.gov. uk/government/uploads/system/uploads/attachment_data/file/800907/GCRF_ Foundation_Evaluation_Inception_Report.pdf, accessed 21 February 2021.

BHCC (2020) Protecting our downland for future generations, https://www.brighton-hove. gov.uk/news/2020/protecting-our-downland-future-generations, accessed 17/12/2020.

Borie, M., Ziervogel, G., Taylor, F.E., Millington, J.D.A., Sitas, R., \& Pelling, M. (2019) Mapping (for) resilience across city scales: An opportunity to open-up conversations for more inclusive resilience policy? Environmental Science and Policy 99: 1-9.

Brandt, P., Ernst, A., Gralla, F., Luederitz, C., Lang, D.J., Newig, J., Reinert, F., Abson, D.J., \& von Wehrden, H.A. (2013) Review of transdisciplinary research in sustainability science. Ecological Economis 92: 1.

Brown, K. (2013) Global environmental change 1: A social turn for resilience? Progress in Human Geography [online first].

Charli-Joseph, L., Siqueiros-García, J.M., Eakin, H., Manuel-Navarrete, D. and Shelton, R. (2018) Promoting agency for social-ecological transformation: A transformationlab in the Xochimilco social-ecological system. Ecology and Society 23(2): 46. 
Clarke, A. (1999) Evaluation research: An introduction to principles, methods and practice. London: Sage.

Davidson, D.J. (2010) The applicability of the concept of resilience to social systems: Some sources of optimism and nagging doubts. Society \& Natural Resources 23: 1135-1149.

Douthwaite, B., Mayne, J., McDougall, C. and Paz-Ybarnegaray, R. (2017) Evaluating complex interventions: A theory-driven realist-informed approach. Evaluation 23(3): 294-311, doi: 10.1177/1356389017714382 (accessed 28 May 2020).

Hackett, E., \& Eakin, H. (2015) ISSC 'Transformations to Sustainability' programme concept note- Water governance challenges, mexico city and phoenix research note from the ASU Water Workshop, 12 December 2014, STEPS Centre and Arizona State University.

ISSC (2012) Transformative cornerstones of social science research for global change. Paris: International Social Science Council.

Ely, A., Marin, A., Charli-Joseph, L., Abrol, D., Apgar, M., Atela, J., Ayre, B., Byrne, R., Choudhary, B. K., Chengo, V., Cremaschi, A., Davis, R., Desai, P., Eakin, H., Kushwaha, P., Marshall, F., Mbeva, K., Ndege, N., Ochieng, C., Ockwell, D., Olsson, P., Oxley, N., Pereira, L,. Priya, R., Tigabu, A., Van Zwanenberg, P., \& Yang, L. (2020) Structured collaboration across a Transformative Knowledge Network: Learning across disciplines, cultures and contexts? Sustainability 12(6): 2499. doi: 10.3390/ su12062499.

Ely, A.V., \& Wach, E. (2018) Endings and beginnings: Project-based work within wider transformations, https://steps-centre.org/blog/endings-and-beginnings-projectbased-work-within-wider-transformations/, accessed 16/12/2020.

Feola, G. (2015) Societal transformation in response to global environmental change: A review of emerging concepts. Ambio 44: 376-390.

Folke, C., Hahn, T., Olsson, P., \& Norberg, J. (2005) Adaptive governance of socialecological systems. Annual Review of Environment and Resources 30: 441-473.

Gramsci, A. (1971) Selections from the Prison notebooks of Antonio Gramsci. New York: International Publishers.

Hackett, E., \& Eakin, H. (2015) ISSC 'Transformations to Sustainability' programme concept note- Water governance challenges, Mexico City and Phoenix research note from the ASU water workshop, 12 December 2014, STEPS Centre and Arizona State University, https://steps-centre.org/wp-content/uploads/ISSC-Concept-note_ASU. pdf, accessed 29/9/2020.

Leach, M., Reyers, B., Bai, X., Brondizio, E. S., Cook, C., Díaz, S., Espindola, G., Scobie, M., Stafford-Smith, M., \& Subramanian, S. M. (2018) Equity and sustainability in the Anthropocene: a social-ecological systems perspective on their intertwined futures. Global Sustainability 1: e13.

Lebel, J., \& McLean, R. (2018) A better measure of research from the global south. Nature 559: 23-26.

Mayne, J. (2008) Contribution analysis: An approach to exploring cause and effect, ILAC Brief 16, Institutional Learning and Change (ILAC) Initiative, https://cgspace.cgiar.org/ handle/10568/70124 (accessed 28 May 2020).

Marx, K. (1976) Capital: A critique of political economy, Volume 1. Harmondsworth: Penguin.

Marshall, F., Dolley, J., \& Priya, R. (2018) Transdisciplinary research as transformative space making for sustainability: Enhancing propoor transformative agency in periurban contexts. Ecology and Society 23(3). doi: 10.5751/ES-10249-230308.

Meadowcroft, J. (2009) What about the politics? Sustainable development, transition management, and long-term energy transitions. Policy Sciences 42(4): 323. 
Moser, S. (2016) Can science on transformation transform science? Lessons from codesign. Current Opinion in Environmental Sustainability 20: 106-115.

Norström, A.V., Cvitanovic, C., Löf, M.F., et al. (2020) Principles for knowledge co-production in sustainability research. National Sustainable. doi: 10.1038/ s41893-019-0448-2.

Ofir, Z., Schwandt, T., Duggan, C., \& McLean, R. (2016) Research quality plus (RQ+): $A$ holistic approach to evaluating research. Canada: International Development Research Centre.

O’Brien, K., \& Sygna, L. (2013) Responding to climate change: The three spheres of transformation. Proceedings of Transformation in a Changing Climate (June): 16-23.

Olsson, P., Folke, C., \& Berkes, F. (2004) Adaptive co-management for building resilience in social-ecological systems. Environmental Management 34: 75-90.

Patton, M.Q. (2010) Developmental evaluation: Applying complexity concepts to enhance innovation and use. New York: Guilford Press.

Pawson, R., \& Tilley, N. (1997) Realistic evaluation. London: Sage Publications.

Pereira, L.M., Karpouzoglou, T., Frantzeskaki, N., \& Olsson, P. (2018) Designing transformative spaces for sustainability in social-ecological systems. Ecology and Society 23(4): 32 .

Pereira, L., Frantzeskaki, N., Hebinck, A., Charli-Joseph, L., Drimie, S., Dyer, M., Eakin, H., Galafassi, D., Karpouzoglou, T., Marshall, F., Lee Moore, M., Olsson, P., Siqueiros-García, J.M., van Zwanenberg, P., \& Vervoort, J.M. (2019) Transformative spaces in the making: Key lessons from nine cases in the Global South. Sustainability Science 15: 161-178.

Polanyi, K. (1944) The great transformation: The political and economic origins of our time. Boston: Beacon Press.

Prieto Martin, P., Apgar, M., \& Hernandez, K. (2020) Adaptive management in SDC: Challenges and opportunities. Brighton: Institute of Development Studies.

Punton, M., \& Vogel, I. (2020) Keeping it real: Using mechanisms to promote use in the realist evaluation of the building capacity to use research evidence program. New Directions for Evaluation 2020(167): 87-100.

Ramalingam, B., Wild, L., \& Buffardi, A.L. (2019) Making adaptive rigour work. Brighton: Institute of Development Studies.

Raudsepp-Hearne, C., Peterson, G.D., Bennett, E.M., Biggs, R., Norstrom, A.V., Pereira, L., Vervoort, J., Iwaniec, D.M., McPhearson, T., Olsson, P., Hichert, T., Falardeau, M., \& Aceituno, A.J. (2019) Seeds of good anthropocenes: Developing sustainability scenarios for Northern Europe. Sustainability Science. doi: 10.1007/ s11625-019-00714-8.

Ruizpalacios, B., Charli-Joseph, L., Eakin, H., Siqueiros-García, J.M., ManuelNavarrete, D., \& Shelton, R. (2019) The transformation laboratory of the social-ecological system of Xochimilco, Mexico City: Description of the process and methodological guide. Mexico City: LANCIS-IE, UNAM.

Ruizpalacios, B., Charli-Joseph, L., Eakin, H., Mario Siqueiros-García, J., \& Shelton, R. (2018) Creating bridges through the Pathways to Sustainability game, https://steps-centre. $\mathrm{org} / \mathrm{blog} / \mathrm{creating}$-bridges-through-the-pathways-to-sustainability-game/, accessed $16 / 12 / 2020$.

Scoones, I., Newell, P., \& Leach, M. (Eds) (2015) The politics of Green transformations. Abingdon: Routledge.

Scoones, I., Stirling, A., Abrol, D., Atela, J., Charli-Joseph, L., Eakin, H., Ely, A., Olsson, P., Pereira, L., Priya, R., van Zwanenberg, P., \& Yang, L. (2018) Transformations to sustainability, STEPS Working Paper 104. Brighton: STEPS Centre. 
Scoones, I., Leach, M., Smith, A., Stagl, S., Stirling, A., \& Thompson, J. (2007) Dynamic systems and the challenge of sustainability, STEPS Working Paper 1, Brighton: STEPS Centre,

Scoones, I., Stirling, A., Abrol, D., Atela, J., Charli-Joseph, L., Eakin, H., Ely, A., Olsson, P., Pereira, L., Priya, R., van Zwanenberg, P., \& Yang, L. (2020) Transformations to sustainability: Combining structural, systemic and enabling approaches. Current Opinion in Environmental Sustainability. doi:10.1016/j.cosust.2019.12.004.

Smith, A., Voß, J-P., \& Grin, J. (2010) Innovation studies and sustainability transitions: The allure of the multi-level perspective and its challenges. Research Policy 39(4): 435-448.

Stirling, A., Leach, M., Mehta, L., Scoones, I., Smith, A., Stagl, S., \& Thompson, J. (2007) Empowering designs: Towards more progressive appraisal of sustainability, STEPS Working Paper 3, Brighton: STEPS Centre.

Ton, G., Mayne, J., Delahais, T., Morell, J., Befani, B., Apgar, M., \& O’Flynn, P. (2019) Contribution analysis and estimating the size of effects: Can we reconcile the possible with the impossible? CDI Practice Paper.

Tschakert, P., \& Dietrich, K.A. (2010) Anticipatory learning for climate change adaptation and resilience. Ecology and Society 15(2): 11.

UKRI (2019) UKRI GCRF global interdisciplinary research hubs, https://www.ukri.org/ wp-content/uploads/2020/10/UKRI-22102020-GCRF-Hub-booklet-June-2019. pdf, accessed 21 February 2021).

UN (2020) Climate Change and COVID-19: UN urges nations to 'recover better', April 22 https://www.un.org/en/un-coronavirus-communications-team/un-urgescountries-\%E2\%80\%98build-back-better\%E2\%80\%99, accessed 16/12/2020.

Van Zwanenberg, P., Marin, A., \& Ely, A. (2016) How do we end the dominance of rich countries over sustainability science? STEPS Centre: Brighton, UK. Available online: https:// steps-centre.org/blog/how-do-we-end-the-dominance-of-rich-countries-oversustainability-science/ (accessed on 9 September 2019).

van Zwanenberg, P., Cremaschi, A., Obaya, M., Marin, A., \& Lowenstein, V. (2018) Seeking unconventional alliances and bridging innovations in spaces for transformative change: the seed sector and agricultural sustainability in Argentina. Ecology and Society 23(3): 11.

West, S., Haider, J., Sinare, H., \& Karpouzoglou, T. (2014) Beyond divides: Prospects for synergy between resilience and pathways approaches to sustainability, STEPS Working Paper 65, Brighton: STEPS Centre.

Westley, F.R., Tjornbo, O., Schultz, L., Olsson, P., Folke, C., Crona, B., \& Bodin, Ö. (2013) A theory of transformative agency in linked social-ecological systems. Ecology E Society 18: 1-16.

Wittmayer, J.M., \& Schäpke, N. (2014) Action, research and participation: roles of researchers in sustainability transitions. Sustainability Science 9(4): 483-496.

Yang, L., \& Walker, R. (2020) Poverty, shame and ethics in contemporary China. Journal of Social Policy 49(3): 564-581. 